\title{
Cérebro transparente com a histologia CLARITY
}

\author{
Transparent brain wtih CLARITY histology
}

Fábio Zanini' ${ }^{1}$ Julia Calixto Gonçalves ${ }^{2}$, Gabriel Maisonnave Arisi ${ }^{3}$

Zanini F, Gonçalves JC, Arisi GM. Cérebro transparente com a histologia CLARITY / Transparent brain with CLARITY histology. Rev Med (São Paulo). 2016 jan.-mar.;95(1):1-5.

RESUMO: A microscopia e as técnicas histológicas avançaram muito nossa compreensão da estrutura celular do tecido nervoso. No entanto, a complexa organização tridimensional dos neurônios, células gliais e da vasculatura é perdida no fatiamento do tecido nervoso para sua observação ao microscópio. Métodos elaborados e demorados são utilizados para reconstruir a organização tridimensional dessas células. A técnica histológica CLARITY preserva a estrutura das proteínas celulares "in situ" e torna o tecido nervoso transparente à luz, removendo a grande quantidade de lipídios presente nesse tecido, permitindo estudos envolvendo grandes volumes de diferentes regiões do cérebro. Esta histologia é feita por perfusão de monômeros que, após a polimerização criam um hidrogel híbrido da proteína com o monômero, permitindo a remoção eletroforética dos lipídios, tornando o tecido transparente à luz. Isso permite a visualização de grandes volumes do tecido em microscópios de fluorescência após marcação das proteínas de interesse por imunohistoquímica.

DESCRITORES: Eletroforese; Histoquímica; Fluorescência; Morfologia; Permeabilidade Macromolecular; Macromoléculas in Situ.

\begin{abstract}
Microscopy and histological techniques had greatly advanced our understanding of the fine cellular structure of nervous tissue. Nonetheless, the complex tridimensional organization of neurons, glial cells and vasculature is lost in sectioning the brain in order to analyze it under the microscope. Laborious and time consuming methods are employed to reconstruct the 3D organization of cells. Advanced histological techniques like CLARITY, that preserves the cellular protein structure in situ and renders the nervous tissue transparent to light by removing the cellular lipid layers, will allow studies encompassing large volumes of different brain regions. This histology is performed by perfusion of hydrogel monomers that after polymerization creates a protein-monomer hybrid that allows electrophoretic removal of the lipids. The transparent hydrogel can be scanned in a fluorescent microscope after protein immunolabeling.
\end{abstract}

KEYWORDS: Electrophoresis; Immunohistochemistry; Fluorescence; Morphology; Macromolecular permeability; Macromolecules in Situ.

Trabalho apresentado oralmente no $4{ }^{\circ}$ Brazilian Internacional Congress of Medical Students (BRAINCOMS) na Universidade Federal de São Paulo, Escola Paulista de Medicina, 17 de outubro de 2015.

1. Aluno do quarto ano da graduação de medicina da Escola Paulista de Medicina da Universidade Federal de São Paulo (EPMUNIFESP). Bolsista de Iniciação Científica FAPESP (Processo no 2015/04098-0). E-mail: fabiozaninis@gmail.com.

2. Aluna do terceiro ano da graduação de medicina da Escola Paulista de Medicina da Universidade Federal de São Paulo (EPMUNIFESP). Bolsista de Iniciação Científica do programa Jovens Talentos para Ciência da CAPES.

3. Professor Adjunto do Departamento de Fisiologia, Escola Paulista de Medicina, Universidade Federal de São Paulo - UNIFESP. Endereço para correspondência: Gabriel Arisi. Laboratório de Neurobiologia, Prédio Pesquisa II. Rua Pedro de Toledo, 669, $3^{\circ}$ andar, L3A. Vila Clementino, São Paulo - SP. Email: arisi@unifesp.br 


\section{INTRODUÇÃO}

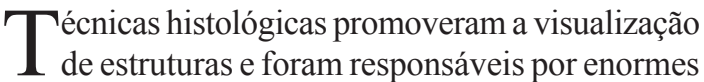
avanços na compreensão das funções celulares dos organismos. Contudo, em alguns tecidos, como o nervoso, as técnicas mais utilizadas acabam por não permitir uma visão integral das estruturas que o formam, prejudicando o entendimento de seu funcionamento pelas dificuldades que as técnicas mais usadas até então impõem aos dados obtidos, dentre elas o fato de que as reconstruções podem ser feitas apenas em um volume pequeno de tecido ${ }^{1}$ e que existem erros consideráveis na reconstrução. A grande dificuldade encontrada na visualização do tecido nervoso íntegro diz respeito à quantidade de lipídeos encontrados nele, dando-o considerável opacidade. Grande parte desses lipídios é advinda da bainha de mielina formada pelos oligodendrócitos. Até então a eliminação dessa massa lipídica alterava profundamente a forma do órgão, mas a técnica CLARITY permite a retirada por eletroforese dos lipídeos sem comprometer a estrutura protéica do tecido nervoso, promovendo a fixação simultânea do tecido enquanto os lipídios são retirados. Assim, o tecido nervoso mantém sua estrutura global e fica transparente à luz e poroso a macromoléculas ${ }^{1}$ sendo, portanto, passível de coloração, permitindo a verificação das moléculas marcadas em seu local de origem. Isto não era possível mesmo com técnicas mais modernas como a imunohistoquímica por necessitar de fatias finas de tecido com poucos micrômetros de espessura, ou com técnicas de Biologia Molecular como o Western Blot, por exemplo, pela necessidade de extrair as macromoléculas de interesse.

A técnica CLARITY se assemelha a um Western Blot, no qual ao invés de extrairmos as proteínas presentes no tecido e colocarmos em um gel de poliacrilamida, mantemos as proteínas em seus locais de origem e produzimos um gel dentro do tecido que se deseja estudar - no nosso caso o tecido nervoso. Assim, conseguimos verificar grande parte da composição protéica do tecido após retirarmos por eletroforese a massa lipídica, que compõe o cérebro. Isso nos permite um estudo mais detalhado e confiável de todas as famílias de moléculas presentes nos tecido do animal e suas respectivas funções. A técnica CLARITY também é promissora no estudo de peças de tecido humano, mesmo os que se encontram já fixados, como os presentes nos laboratórios de anatomia das Universidades. Com o CLARITY é possível também lavar a imunomarcação anterior com o detergente SDS e marcar outras proteínas, associando assim uma imagem de um grande volume de diferentes proteínas de interesse a um menor número de animais experimentais utilizados.

Assim, o objetivo do presente trabalho foi implantar a técnica histológica CLARITY para o estudo do sistema nervoso central, para que, no futuro, possamos realizar um estudo morfológico de neurônios, micróglias e astrócitos.

\section{MATERIAIS E MÉTODOS}

Todos os procedimentos descritos foram adaptados do protocolo original presente no artigo de Chung et al. ${ }^{2}$.

\section{Preparação do Tecido}

Utilizamos 6 ratos do tipo Wistar (IACUC/CEUA 6744240414); anestesiados com 90mg/kg de tiopental sódico.

Após anestesia, iniciamos a perfusão, injetando as soluções no ventrículo esquerdo com a utilização de bomba rotatória. Na primeira etapa lavamos os tecidos do animal com solução salina $(\mathrm{NaCl}$ 0,9\%), infundindo em seguida a Solução de Perfusão Hidrogel (Tabela 1) e lavando novamente com solução salina. Após perfusão os cérebros dos animais foram extraídos e deixados por $72 \mathrm{hs}$ em tubos de $50 \mathrm{ml}$, contendo $20 \mathrm{ml}$ de Solução de Perfusão Hidrogel à $5^{\circ} \mathrm{C}$.

Tabela 1: Solução de perfusão hidrogel, tendo a acrilamida como o principal constituinte do futuro polímero

\begin{tabular}{lc}
\hline \multicolumn{2}{c}{ Solução de Perfusão Hidrogel } \\
\hline Acrilamida & $4 \%$ \\
\hline BIS & $0,05 \%$ \\
\hline VA-044 & $0,25 \%$ \\
\hline PBS & $0,1 \mathrm{M}$ \\
\hline Paraformaldeído & $4 \%$ \\
\hline
\end{tabular}

\section{Blocagem}

Trabalhando a maior parte do tempo dentro de um dessecador, inserimos $\mathrm{N}_{2}(\mathrm{~g})$ dentro dos tubos de $50 \mathrm{ml}$, que acondicionavam os cérebros embebidos em solução de perfusão. Em seguida os tubos foram colocados dentro do dessecador, com as tampas apenas apoiadas acima deles. Injetamos $\mathrm{N}_{2}(\mathrm{~g})$ no dessecador e criamos dentro dele uma câmara de $\mathrm{N}_{2}(\mathrm{~g})$; após isso, com o auxílio de uma bomba de vácuo, retiramos parte do gás nitrogênio e mantivemos a situação por 10 minutos. A retirada do vácuo foi feita com a injeção de $\mathrm{N}_{2}(\mathrm{~g})$. Todo esse processamento visou à retirada do $\mathrm{O}_{2}(\mathrm{~g})$ do meio, no qual os tecidos a serem blocados se encontravam visto que a presença do gás prejudicaria a formação do polímero. Após passar por esse processo todos os tubos de ensaio foram fechados e colocados em banho térmico a $37^{\circ} \mathrm{C}$ por 3 horas.

\section{Limpeza}

Terminado o banho térmico, retiramos o tecido juntamente com o gel, que se formou dentro dos tubos de ensaio de $50 \mathrm{ml}$, cortamos o excesso de polímero aderido e colocamos novamente o tecido blocado dentro de tubos de $50 \mathrm{ml}$, agora contendo $30 \mathrm{ml}$ de solução de limpeza (Tabela 2). Os seis cérebros passaram por três banhos de $24 \mathrm{~h}$, cada 
um deles com as seguintes especificações:

- $1^{\circ}$ banho: $24 \mathrm{~h}$ à temperatura ambiente e sob agitação;

- $2^{\circ}$ banho: $24 \mathrm{~h}$ à $37^{\circ} \mathrm{C}$;

- $3^{\circ}$ banho: $24 \mathrm{~h}$ à $37^{\circ} \mathrm{C}$.

Entre as trocas de banho foi necessário retirar os demais excessos de polímero aparentes aderidos ao tecido.

Tabela 2: Solução de limpeza, a qual contém grande quantidade de SDS para a remoção dos lipídios

\begin{tabular}{l|l}
\hline \multicolumn{2}{c}{ Solução de Limpeza } \\
\hline Ácido Bórico & $200 \mathrm{mM}$ \\
\hline $\mathrm{SDS}$ & $4 \%$ \\
\hline $\mathrm{NaOH}$ & correção do pH para 8.5 \\
\hline
\end{tabular}

\section{Eletroforese do Tecido}

Construímos uma câmara de eletroforese seguindo instruções presentes no documento produzido pelo autor da técnica ${ }^{3}$, adaptando-a a nossa realidade. As principais alterações feitas por nós foram a utilização de um recipiente de $80 \mathrm{ml}$, eletrodos de platina menores $-3 \mathrm{~cm}$ por $1 \mathrm{~cm}$, conforme Figura 1a - e de diâmetro também menor - 0,3 mm.

Introduzimos o tecido na câmara após os três processos de limpeza e completamos o volume da câmara com a Solução de Limpeza. Utilizando uma bomba, circulamos um volume maior de Solução de Limpeza dentro da câmara de eletroforese com temperatura controlada e constante, com intervalo de escolha entre $37^{\circ} \mathrm{C}-50^{\circ} \mathrm{C}$. Os eletrodos foram alimentados com uma fonte de voltagem controlada e constante, a qual tem intervalo de escolha entre $10 \mathrm{~V}-60 \mathrm{~V}$. A preparação ficou nessa condição por diversos dias, até o tecido tornar-se translúcido. Quanto maior a voltagem aplicada e a temperatura, mais rápido é esse processamento.

\section{Lavagem}

Após os diversos dias de eletroforese, lavamos o tecido com PBST ( $0,1 \%$ TritonX em PBS $1 \mathrm{X})$, duas vezes, sendo o período de cada lavagem de $24 \mathrm{~h}$.

\section{Coloração}

Foi realizada reação imunohistoquímica para Ionized Calcium-binding Adapter Molecule 1 (Iba-1) marcadora de células da micróglia.

Resumidamente, o bloco de hidrogel foi incubado por 2 dias a $37{ }^{\circ} \mathrm{C}$ em anti-Iba-1 (Wako, cat 019-19741) diluído 1:500 em 0,1\% Triton X-100 em PBS em tampão $1 \mathrm{M}$ de borato de sódio. Depois da incubação com anticorpo primário o bloco foi lavado na mesma solução tampão por 1 dia a $37^{\circ} \mathrm{C}$ e posteriormente incubado com anticorpo secundário anti-Ig de coelho marcado com GFP por 2 dias.

\section{Microscopia}

Para visualização da marcação imunohistoquímica um bloco de hidrogel (1 $\mathrm{mm}$ de espessura) foi montado em lâminas adaptadas e observado em microscópio de fluorescência confocal Leica TCS SP8 localizado no laboratório multiusuário 4 no Instituto de Farmacologia da UNIFESP.

\section{RESULTADOS}

Obtivemos sucesso em todo o preparo do tecido para a eletroforese, controlando bem todas as reações necessárias para tal, principalmente a polimerização térmica (Figura 1-D). Também conseguimos produzir uma câmara de eletroforese funcional e com tamanho adequado para o cérebro de ratos Wistar (Figura 1-B e 1-C) - visto que todo o desenvolvimento da técnica CLARITY originalmente foi feito com cérebros de camundongo.

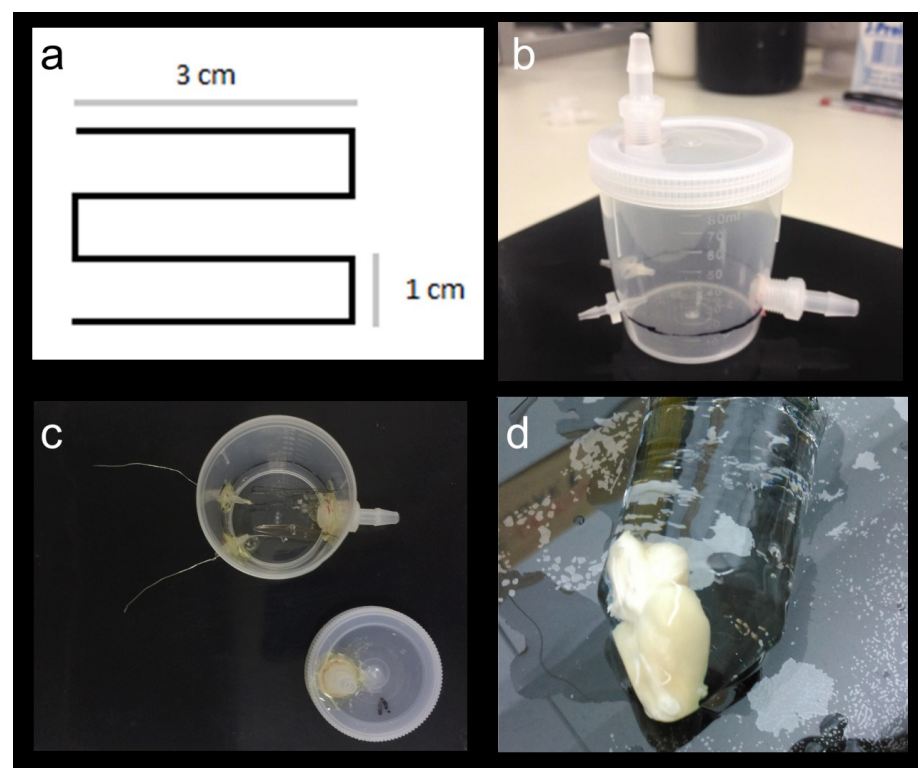

Figura 1. Desenho esquemático dos eletrodos de platina (A) Câmara de eletroforese construída (B) vista lateral e superior (C). Encéfalo de rato Wistar embebido em hidrogel após polimerização e antes da eletroforese e remoção térmica dos lipídios 
Utilizando o obtido, fizemos a eletroforese do cérebro de 6 animais e após $72 \mathrm{hs}$ de eletroforese sob diferença de potencial de $30 \mathrm{~V}$ e temperatura de $37^{\circ} \mathrm{C}$ nas primeiras $48 \mathrm{~h}$ e $42^{\circ} \mathrm{C}$ nas demais horas obtivemos um cérebro com adequado grau de transparência (Figura 2). A análise de uma das seis amostras com imunohistoquímica para Iba-1(bloco parcial de $1 \mathrm{~mm}$ ) em microscopia confocal permitiu a visualização de inúmeras células de micróglia com seus corpos celulares e processos, fornecendo uma excelente visualização da morfologia dessas células (Figura 3) e dando indícios iniciais que todo o procedimento pelo qual o tecido é submetido não leva a destruição da arquitetura protéica do mesmo.
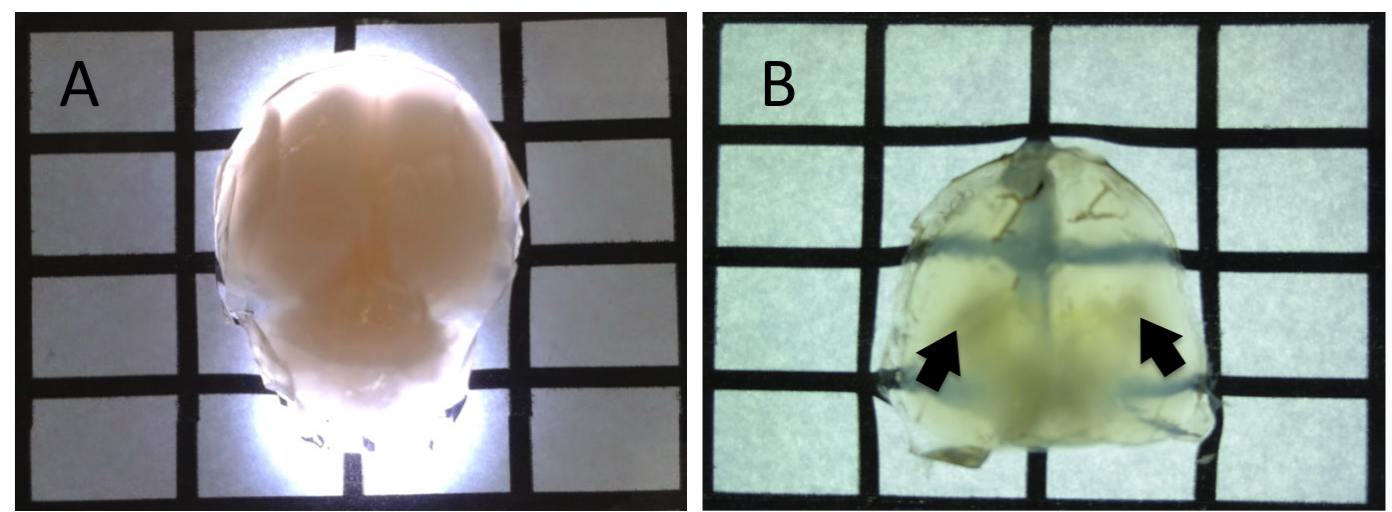

Figure 2. Encéfalo de rato Wistar antes (A) e depois (B) da eletroforese e remoção térmica dos lipídios. O tecido tornouse transparente após a remoção parcial dos lípides. Algumas estruturas do cérebro, como os tálamos são visíveis (flechas)

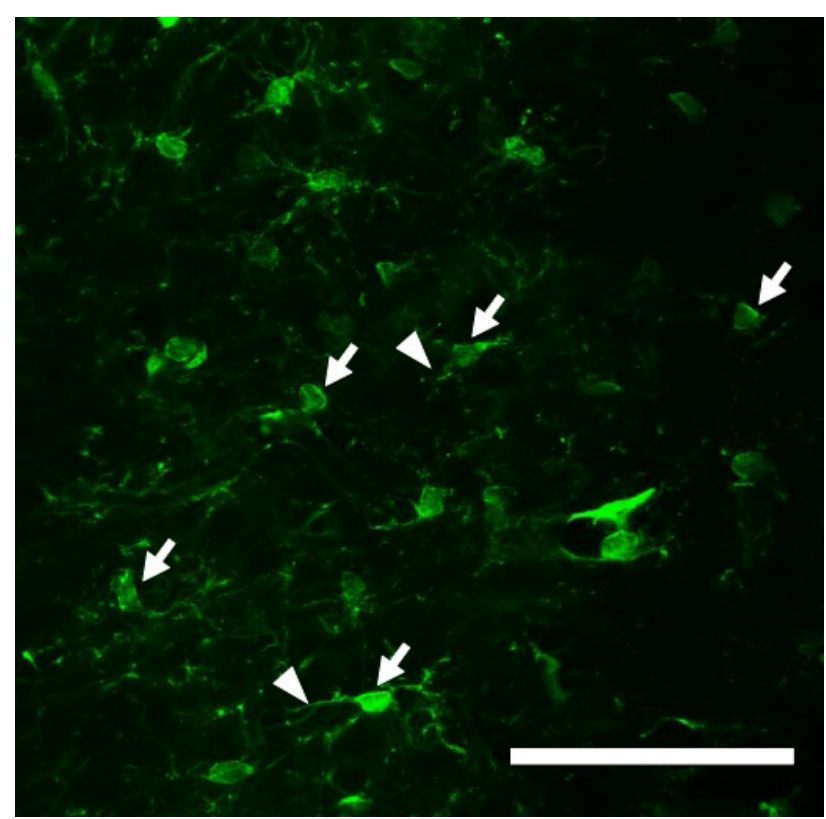

Figura 3. Imunohistoquímica para proteína Iba-1 permitindo a visualização das células da micróglia em estado quiescente com clara definição dos corpos celulares (flechas) e processos (cabeças de flecha). Essa imagem resulta da soma de 30 imagens que cobrem uma profundidade de $150 \mu \mathrm{m}$ no neocortex. Barra $=30 \mu \mathrm{m}$

\section{DISCUSSÃO E CONCLUSÕES}

Com base em nossos dados inicias sugere-se que essa adaptação da histologia CLARITY permite uma visualização tridimensional "in situ" de proteínas que compõem o encéfalo do animal em estudo, permitindo a aquisição de uma enorme quantidade de dados com qualidade bem superior aos obtidos por procedimentos que envolvem a reconstrução da tridimensionalidade do encéfalo. Sugere-se portanto, também, que o CLARITY possa ser utilizado na rotina de qualquer laboratório de neurociência interessado no estudo da estrutura protéica do Sistema Nervoso Central.

A técnica, porém, tem grande custo por animal tanto no preparo do tecido que visa deixá-lo transparente, como na imunocoloração, utilizando grande quantidade de anticorpos por espécime. Também não permite o estudo de outras macromoléculas como os lipídios, que são removidos durante o preparo do tecido.

Como perspectivas futuras do trabalho estamos desenvolvendo um sistema que permite a preparação de quatro tecidos simultaneamente, através de um sistema de câmeras com comunicação hidráulica, mas com sistemas elétricos individualizados, o qual facilitaria nossas preparações economizando tempo e solução de limpeza. Também está sendo construído em nosso laboratório um microscópio, conhecido como microscópio de "lençol de luz". Esse equipamento funciona como um tomógrafo e nos permitirá analisar o tecido transparente integralmente, não sendo necessário realizar cortes grossos como o de $1 \mathrm{~mm}$ realizado na análise supracitada. 
Agradecimentos e suporte financeiro: Fabio Zanini, recebe bolsa de iniciação científica (FAPESP 2015/04098-0). Gabriel Maisonnave Arisi é o responsável pelo projeto de pesquisa "Implantação da histologia clarity e microscopia de fluorescência planar para o estudo do sistema nervoso" (Auxílio FAPESP N. : 2014/21984-2). Agradecemos a Clivandir Silva pelo suporte técnico.

\section{REFERÊNCIAS}

1. Chung K, Wallace J, Kim SY, Kalyanasundaram S, Andalman AS, Davidson TJ, Mirzabekov JJ, Zalocusky KA, Mattis J, Denisin AK, Pak S, Bernstein H, Ramakrishnan C, Grosenick L, Gradinaru V, Deisseroth K. Structural and molecular interrogation of intact biological systems. Nature. 2013;497:332-7. doi:10.1038/nature12107.
2. Chung K, Deisseroth K. CLARITY for mapping the nervous system. Nature Methods. 2013;10(6):508-13.

3. CLARITY Forum. Available from: http://forum. claritytechniques.org/. 